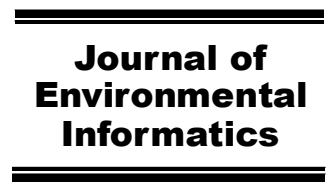

www.iseis.org/jei

\title{
Prediction of Future Phosphate Rock: A Demand Based Model
}

\author{
B. $\mathrm{Li}^{1}$, I. Boiarkina ${ }^{1}$, B. Young ${ }^{1}$, W. Yu ${ }^{1, *}$, N. Singhal ${ }^{2}$ \\ ${ }^{1}$ Department of Chemical \& Materials Engineering, University of Auckland, Private Bag 92019, Auckland, New Zealand \\ ${ }^{2}$ Department of Civil \& Environmental Engineering, University of Auckland, Private Bag 92019, Auckland, New Zealand
}

Received 18 March 2014; revised 4 January 2016; accepted 10 February 2016; published online 4 June 2017

\begin{abstract}
As phosphorus (P) is an essential element and phosphate rock a non-renewable resource that is depleting rapidly, a robust phosphate production model is becoming essential for future resource management. However, the majority of current production models are based on either time series analysis or mathematical regression, neglecting the effect of human demand. Thus, this work proposes a new phosphate rock supply model based on historical phosphorus demand. The population was used in conjunction with the average $\mathrm{P}$ fertilizer consumption as the key parameters for the demand model, which also considered the consumption differences between developed and developing countries. The model results indicate that without proper management phosphate rock will be depleted within the next $70 \sim 140$ years. A conceptual phosphorus management system is proposed and substantial recovery would be required to have a significant impact on the depletion time, on the order of $50 \%$ to defer depletion by 50 years.
\end{abstract}

Keywords: phosphorus, phosphorus depletion, phosphorus management, phosphorus recovery

\section{Introduction}

Phosphorus $(\mathrm{P})$ is an essential element in cell structure, organisms and food production processes. Most of the P currently being used is sourced from mined phosphate rock (P rock), which is a non-renewable resource and has no feasible substitute. Historically, more than $90 \%$ of mined P rock was used for fertilizer to sustain food production (Rawashdeh and Maxwell, 2011; Scholz et al., 2013; Wang et al., 2013).

The world population is expected to exceed 9 billion in 2050 (Lutz et al., 2001), which will lead to an increase in food demand, and P rock demand by extension. Given that P rock is expected to be depleted within the next 100 years (Bennett and Elser, 2011), this may cause geopolitical issues if supply cannot meet demand, as the world's P rock reserves are concentrated in a small number of geographical areas. Morocco, China, Algeria and the USA account for almost $85 \%$ of the world's reserves, with Morocco alone accounting for $77 \%$ (Cooper et al., 2011).

$P$ rock that is easy to access, of higher grade (i.e., with higher P content), and lower contaminant level is always mined first (Sinding-Larsen and Wellmer, 2012). As a result, mining costs increase over time, to the point where economics and mining techniques constrain further mining action. Furthermore, current agricultural $\mathrm{P}$ utilization efficiency is typically low

${ }^{*}$ Corresponding author. Tel: +649923 5027; fax: +6493737421.

E-mail address: w.yu@auckland.ac.nz (W. Yu).

SSN: 1726-2135 print/1684-8799 online

(C) 2018 ISEIS All rights reserved. doi: 10.3808/jei.201700364 nearly $90 \%$ of $\mathrm{P}$ is lost to the environment following primary consumption (Cordell et al., 2009). Such losses enrich the P concentration in local streams, leading to environmental problems such as red tide and eutrophication (Bennett and Elser, 2011). Therefore, it is necessary to have a more in depth understanding of future P rock demand and supply. This would not only highlight future $\mathrm{P}$ rock trends, but also indicate possible effective resource management solutions for a sustainable future.

The current models to predict future P rock supply can be divided into two groups: the static reserve to production model (S-R/P) (Herring and Fantel, 1993) and the dynamic reserve to production model (D-R/P) (Cordell et al., 2010; Van Vuuren et al., 2010). In the S-R/P model, the ratio of Ultimately recoverable reserves (URR) to a certain year's P rock production is used to represent the P rock depletion time (Galvez-Sola et al., 2010). Although the calculation is simple, ignoring production variation, rock grade changes and human demand fluctuations make it unreliable. The D-R/P models, however, tries to predict the future trend by considering annual changes in P rock supply. These models can be used to project the URR or conduct scenario analysis with an estimated URR as a constraint.

Annual P rock supply can be estimated either by mathematical regression (e.g., assuming an exponential growth as done by Herring and Fantel, 1993) or by considering the variations from the demand side. For example, Déry and Anderson (2007) applied the Hubert Curves for P rock supply projection, whose confidence intervals were tested by Vaccari (Vaccari, 2011), showed that omitting a constraining figure for the total remaining reserves decreases the reliability of the dataset. May et al. (2012) used the Gaussian distribution, least squares optimisa- 
tion and cumulative production to estimate the future $\mathrm{P}$ rock supply. However, the supply rate in this model follows a symmetric path, which is unlikely to be realistic (May et al., 2012). Walan et al. (2014) used a gompertz curve to estimate the supply, during which the annual supply is non-symmetric.

All of the above mentioned models applied statistical predictions based on historical P rock supply, which might not reflect changes caused by human demand variation. Therefore, Van Vuuren (2010) predicted the future P rock trend by considering factors from the demand side, such as GDP, population and agricultural development. Similar research has also been conducted by Sverdrup and Ragnarsdottir (2011), Koppelaar and Weikard (2013). Rather than continuous predictions for P rock trend analysis, these models used constant numbers with a different level for each factor (e.g., the population was set to 8.2 and 6.9 billion in 2050 and 2100 respectively) for scenario analysis. This paper improves on past $\mathrm{P}$ rock supply projection models by incorporating human phosphorus demand and considering the phosphorous consumption structure in developed and developing countries separately. This should make the $\mathrm{P}$ rock supply projections more robust.

We address the above mentioned concerns by considering key parameters from human demand and future trends. This not only makes the model validation easier, but also gives a clear view of future P rock supply with time. Different parameters from current $\mathrm{P}$ demand systems were selected and compared in Section 2.1 Historical P fertilizer demand and supply data was then investigated and correlated to historical $P$ rock production to derive a supply model (Section 2.4 ), which was then used for projecting future P rock supply (Section 3.1). A conceptual $\mathrm{P}$ management system was also proposed in Section 4 . The effect of $P$ recovery on the resource lifetime was quantified based on results from the P rock model, made possible by that it is based on demand.

\section{Methodology}

This model uses anthropogenic $\mathrm{P}$ demand to predict future $\mathrm{P}$ rock supply, which consists of time series analysis for $\mathrm{P}$ rock demand prediction and linear regression for $\mathrm{P}$ rock supply estimation. The overall model strategy is shown in Figure 1. Where, $\mathrm{Y}$ is the $\mathrm{P}$ rock supply, D1, P1, F1 are the $\mathrm{P}$ fertilizer demand, population and average $\mathrm{P}$ fertilizer demand from developing countries respectively, and D2, P2, F2 are the corresponding values from developed countries.

\subsection{Independent Variable Selection}

In this study, all $\mathrm{P}$ resources are measured in millions of tonnes of $\mathrm{P}_{2} \mathrm{O}_{5}$. Many different forms of $\mathrm{P}$ are involved in anthropogenic activity, which can be explained using substance flow analysis (shown in Section 2.5).

Previous studies (Li et al., 2015; Cooper and Carliell-Marquet, 2013) indicated that agriculture is the most $\mathrm{P}$ intensive sector in terms of demand, within which $\mathrm{P}$ was mainly used for livestock cultivation and plant production. Thus cereal production, livestock numbers and $\mathrm{P}$ fertilizer application (written

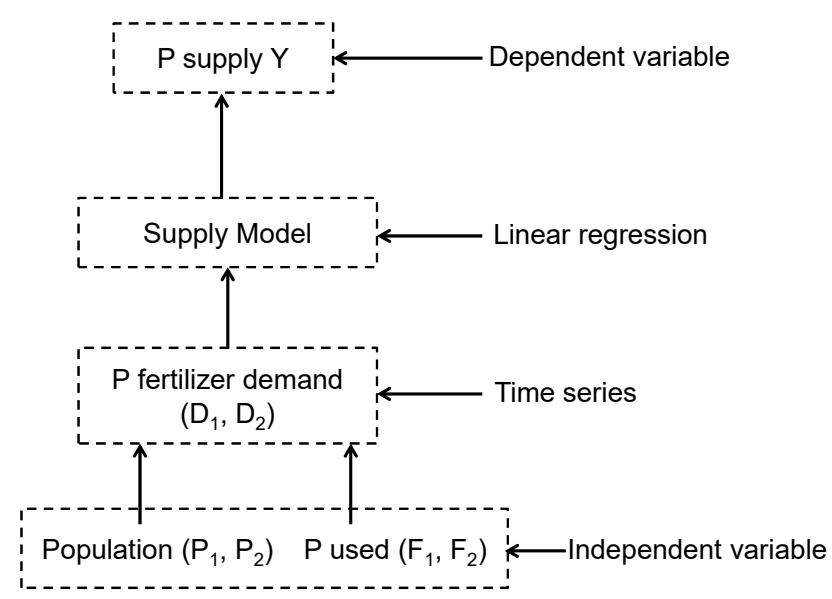

Figure 1. Model development strategy.

as 'P usage') were chosen as the major P parameters. These three parameters together take up $85 \%$ of the total $\mathrm{P}$ demand (Cooper and Carliell-Marquet, 2013). Since population, economic development (GDP) and $\mathrm{P}$ fertilizer price (written as ' $\mathrm{P}$ price') will also affect $P$ rock supply and demand, they were also selected for P rock supply projection. Definitions of selected parameters are listed in Table 1 .

The accuracy of a model is not always improved by including extra parameters, as this can result in over fitting. Furthermore, the increasing complexity would make the model difficult to compute and understand. Thus, the Pearson's correlation indices between different parameters and their relationship with the historical P rock supply (P rock, in short) were calculated and are listed in Table 2.

As shown in Table 2, population, cereal production and $\mathrm{P}$ usage showed a high correlation with historical P rock supply, which indicates a high degree of linear dependence between these parameters. Furthermore, the population and cereal production have high correlation coefficients with other parameters (larger than 0.8), and with each other (0.98). Therefore only a limited number of these parameters needed to be used, as the high collinearity ensures that the selection of a few reflects the others. This assumption can be supported by results from Principal Component analysis (PCA). PCA analysis is conducted on the data set with A to F, six variables (listed in Table 3) for 47 years (from 1961 to 2007).

The PCA loading plot is shown in Figure 2, where the $\mathrm{P}$ usage (F) is far away from other variables. This means that $F$ may affect the phosphate rock production in a different way compared with other variables. It thus explains why we still include $\mathrm{P}$ usage for model construction although its correlation with other parameters are not the highest (Table 3). Since the variables A-E are clustered together, one of them plus variable $F$ will be sufficient to represent the whole data set and different pairs were tested to see how well the pair can represent the whole data set. PCA score plots for different pairs are shown in Figure 3 (the different 47 scores represent the years from 1961 to 2007). Figure 3(a) is the PCA score plot with all variables (A to F); Figure 3(b) is for the variables B and F; Figure 
Table 1. Parameters Selected for Predicting Future P Rock Demand

\begin{tabular}{llll}
\hline Factor & Definition & Unit & Reference \\
\hline GDP & World annual Gross Domestic Product & US dollar & WorldBank, 2014b \\
Population & World annual population & Unit less & WorldBank, 2014b \\
Cereal & World annual crops harvested & Metric tons & WorldBank, 2014b \\
Livestock & World annual meat and milk production from all sources (Include dairy products) & Unitless $^{1}$ & WorldBank, 2014b \\
P price & Annual P price on the international market & Unitless ${ }^{2}$ & USDA, 2014 \\
P usage & Annual worldwide applied P fertilizer & $\mathrm{kg} / \mathrm{Ha}$ & Gapminder Agriculture, 2014 \\
\hline${ }^{1}$ All production compared to the average between 2004 to 2006, which is deemed to be 100. & & \\
${ }^{2}$ Price compared to the average between 1990 to 1992, which is deemed to be 100. & &
\end{tabular}

Table 2. Correlations among Selected Model Parameters

\begin{tabular}{llllllll}
\hline & GDP $(\mathbf{A})$ & Population $(\mathbf{B})$ & Cereal $(\mathbf{C})$ & Livestock (D) & P price (E) & P usage (F) & P rock \\
\hline GDP & 1.00 & 0.94 & 0.93 & 0.97 & 0.89 & 0.74 & 0.76 \\
Population & 0.94 & 1.00 & 0.98 & 0.99 & 0.81 & 0.83 & 0.83 \\
Cereal & 0.93 & 0.98 & 1.00 & 0.97 & 0.82 & 0.89 & 0.89 \\
Livestock & 0.97 & 0.99 & 0.97 & 1.00 & 0.83 & 0.78 & 0.79 \\
P price & 0.89 & 0.81 & 0.82 & 0.83 & 1.00 & 0.69 & 0.71 \\
P usage & 0.74 & 0.83 & 0.89 & 0.78 & 0.69 & 1.00 & 0.92 \\
P rock & 0.76 & 0.83 & 0.89 & 0.79 & 0.71 & 0.92 & 1.00 \\
\hline
\end{tabular}

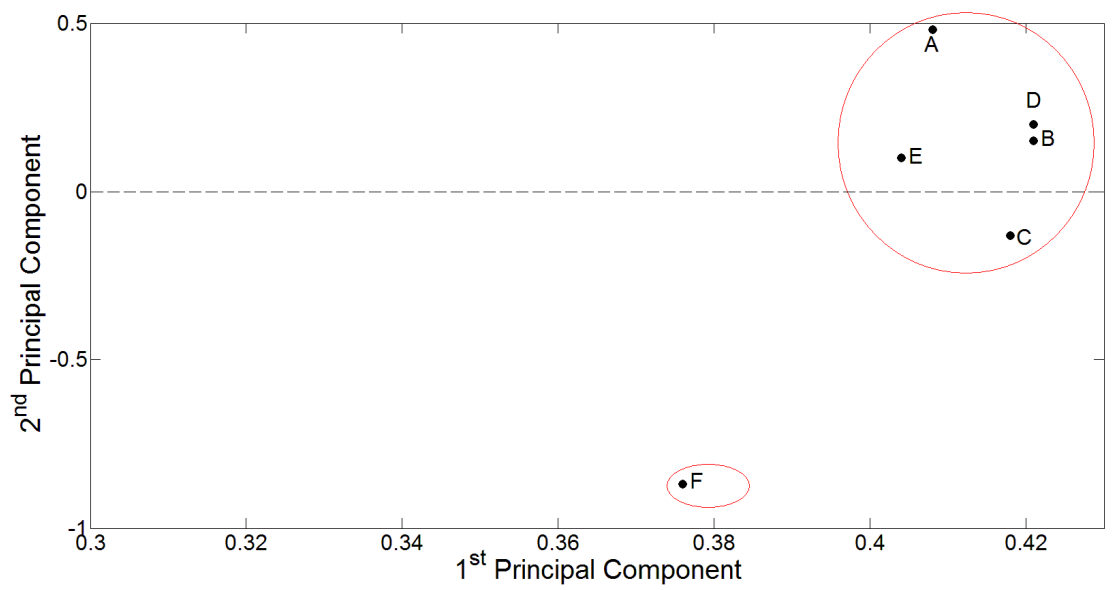

Figure 2. PCA loading plot for parameter selection.

(3c) is for the variables $\mathrm{B}$ and $\mathrm{C}$ and Figure (3d) is for variables $\mathrm{B}$ and D. It can be clearly seen that the score pattern when using variables B and F in Figure (3b) is very similar to the whole data set score plot in Figure (3a), whilst the other two pairs have a larger mismatch.

\subsection{Differences between Developed and Developing Countries}

As per the previous section, the population and $\mathrm{P}$ usage were chosen as the two parameters for predicting the $\mathrm{P}$ rock supply. Since population models have already been developed (Mohr and Evans, 2013), the current work used these by applying them to the P supply and demand system.

However, firstly, it is worthwhile investigating the historical $\mathrm{P}$ fertilizer supply, which can be used to develop a supply model for projecting future trends. The data collected from Gapminder Agriculture (2014) indicated a very large difference in the historical P fertilizer supply of developing and devel- oped countries (definition from WorldBank, (2014a)), which can be seen in Figure 4. The total demand from developed countries has been quite stable for the last 20 years. However, in developing countries, the total demand has shown large fluctuations and has been increasing over time (Figure 4(a)). Based on this observation, global $\mathrm{P}$ rock demand can be divided into two groups: $\mathrm{P}$ demand from developing and developed countries.

To simplify the model, only major countries (in terms of $P$ fertilizer demand) from the developing and developed world were selected (listed in Table 3 ) for the prediction. The fraction of phosphorus fertilizer consumption in the selected countries to the total phosphorus demand was calculated and is shown in Figure 4(b).

Nearly $82 \%$ of total $\mathrm{P}$ fertilizer demand across the developed world since 1960 has been used by the twelve selected developed countries. Within the developing world, however, the $\mathrm{P}$ fertilizer consumed by the twelve selected countries fluc- 

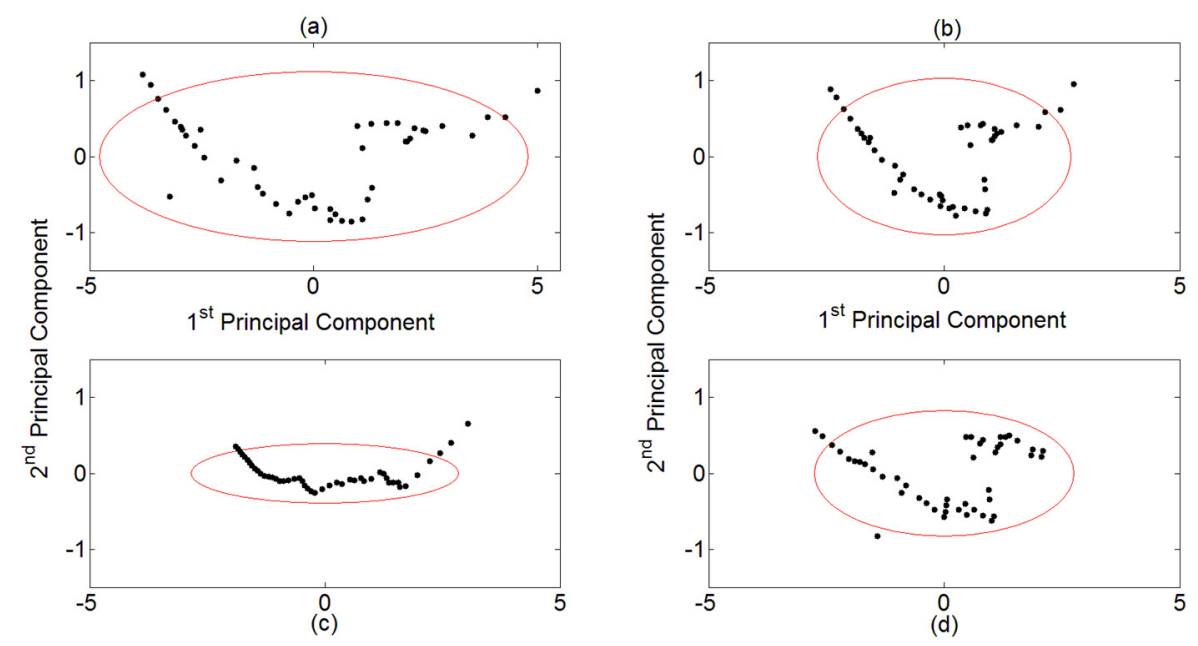

Figure 3. PCA for parameter selection.

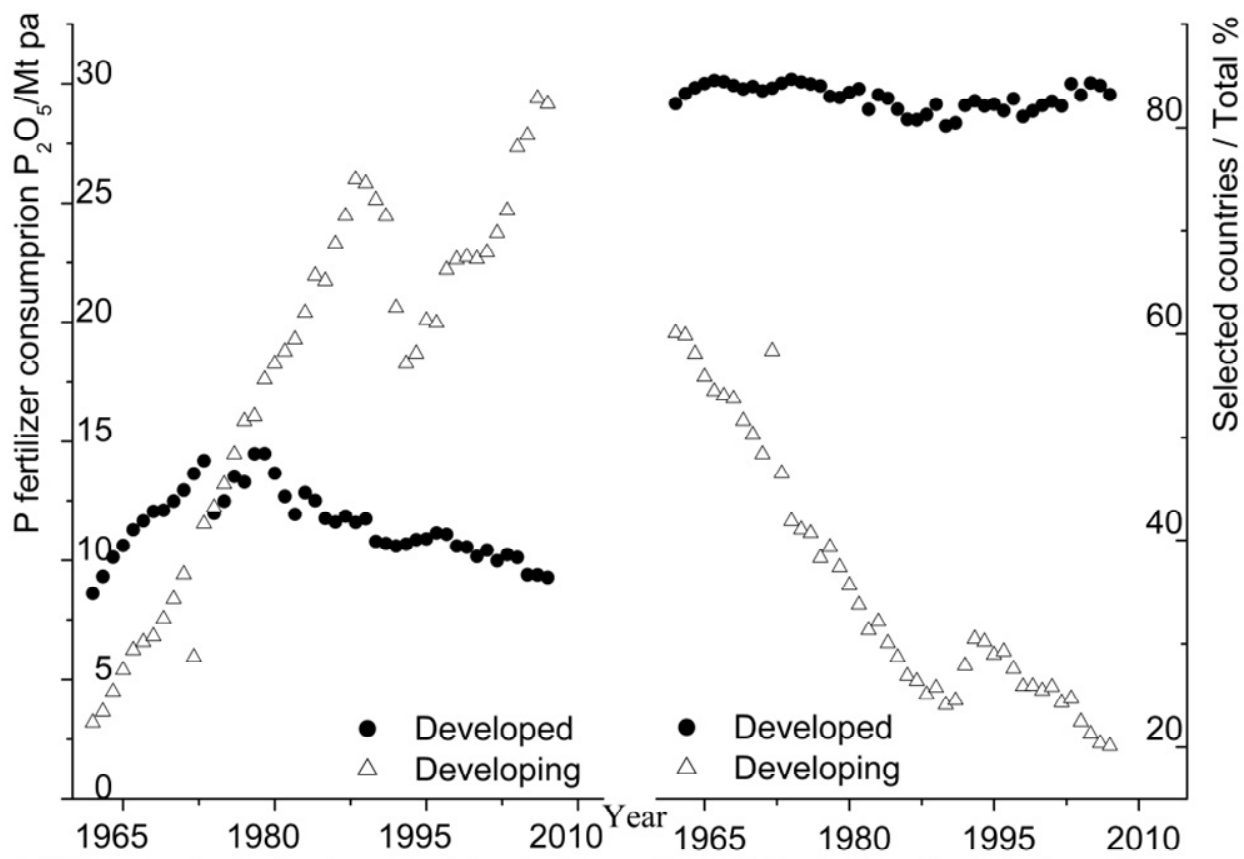

$\begin{array}{lll}\text { a) P Comsumpion in developed and developing world } & \text { b) Evaluation of selected counties }\end{array}$

Figure 4. Phosphorus consumption in developed and developing countries (Data: Gapminder Agriculture, 2014).

tuates significantly over time, which means that the unaccounted for countries contribute significantly to the overall increasing demand in the developing world. Thus, P fertilizer demand in developed countries was investigated based on the twelve countries selected in Table 3 whilst $P$ fertilizer demand in the developing countries was derived from the difference between the worldwide P demand and that in developed countries.

\subsection{Ultimate Recoverable Resource}

To estimate $\mathrm{P}$ rock supply trend, differences among $\mathrm{P}$ re- serves, $\mathrm{P}$ reserve base, $\mathrm{P}$ resources, and ultimately recoverable reserves (URR) were determined. The P reserve is the amount of $\mathrm{P}$ rock that can currently be exploited economically. The $\mathrm{P}$ reserve base is the amount of $P$ rock that has been discovered, but is currently not available for economic or technical reasons. $\mathrm{P}$ resources represent $\mathrm{P}$ in different forms, most commonly as $P$ rock and in soil and water bodies. The ultimately recoverable reserve is the sum of the total historical demand and $\mathrm{P}$ reserve base. Among these four terms, $\mathrm{P}$ resource is popular for considering the influence of technical improvements on $\mathrm{P}$ demand. URR is used to describe the relationship between production 
and reserves. As estimated, the total amount of $P$ rock up to 2013 was 2.2 Gt (Cordell et al., 2009; USGS, 2014).

Table 3. Selected Countries for Modelling the Phosphorus Demand

\begin{tabular}{|c|c|c|c|}
\hline \multicolumn{2}{|c|}{ Developing Countries } & \multicolumn{2}{|c|}{ Developed Countries } \\
\hline Name & W1 & Name & W2 \\
\hline Brazil & $0.65^{*}$ & Australia & 0.43 \\
\hline China & 0.51 & Canada & 0.40 \\
\hline Egypt & $0.65^{*}$ & Germany & 0.40 \\
\hline India & $0.65^{*}$ & Finland & 0.61 \\
\hline Jordan & $0.65^{*}$ & France & 0.37 \\
\hline Morocco & $0.65^{*}$ & UK & 0.27 \\
\hline Mexico & $0.65^{*}$ & Israel & 0.40 \\
\hline Russia & $0.65^{*}$ & Japan & 0.71 \\
\hline Sudan & $0.65^{*}$ & Korea, Rep. & 0.40 \\
\hline Tunisia & $0.65^{*}$ & Netherlands & 0.24 \\
\hline Turkey & 0.81 & New Zealand & 0.55 \\
\hline South Africa & $0.65^{*}$ & United States & 0.81 \\
\hline Average & 0.65 & Average & 0.45 \\
\hline
\end{tabular}

* Information not available. Data calculated from previous literature (Cooper and Carliell-Marquet, 2013; Li et al., 2015).

The discovery rate of phosphate rock reported by governments has remained constant for many years (USGS, 2014). During 1996 to 2010, overall world P rock reserves were estimated at 11 to $18 \mathrm{Gt}$. However, January 2011 saw an enormous P reserves increase, which was revised to $71 \mathrm{Gt}$ in 2014 (USGS, 2014). Rather than new rock reserves being discovered, this change was largely influenced by a report produced by the International Fertiliser Development Centre (IFDC) in 2010, which suggested world P rock reserves were approximately $60 \mathrm{Gt}$ (Van Kauwenbergh et al., 2013). It is still unknown whether the major increase should be considered as true reserves or as reserve base (Cooper and Carliell-Marquet, 2013; Scholz et al., 2013; Burt et al., 2013). In this work, 16 Gt P rock with a $\mathrm{P}_{2} \mathrm{O}_{5}$ content of $30 \%$ was chosen as an assured amount of currently available $\mathrm{P}$ rock (reserve) and 10, 20 and $40 \mathrm{Gt} \mathrm{P}$ rock with $\mathrm{P}_{2} \mathrm{O}_{5}$ contents of $20 \%$ to represent additional reserves (reserve base) available at low, medium and high levels respectively. This is summarized in Table 4.

\subsection{Demand - Supply Model}

In this paper, $\mathrm{P}$ rock demand is the amount of $\mathrm{P}$ being consumed worldwide, considering both direct (e.g. food) and indirect (e.g. fertilizer) consumption. $\mathrm{P}$ rock supply is the $\mathrm{P}$ rock being produced from $\mathrm{P}$ mines. Based on the observations from real data (USGS, 2014; BGS, 2014), the P rock supply is believed to be driven by $\mathrm{P}$ fertilizer demand. However, the exact function is unknown. Thus, some universal nominal functions can be used to develop this relationship.

\subsubsection{Demand Model}

Based on the discussions from Sections 2.1 and 2.2, P rock demand (D) can be represented by the population (P) multip- lied by the P rock demand per person annually $(\mathrm{C})$ :

$$
D_{i}=P_{i} \times C_{i}(i=1,2)
$$

where the subscript numbers 1 and 2 represents $\mathrm{P}$ demands in the developing and developed countries respectively. Since fertilizer is the main application of mined $\mathrm{P}$ rock, $C_{i}$ in Equation (2) can be expressed as:

$$
C_{i}=\frac{F_{i} \times R_{2}}{W_{i} \times R_{1}}
$$

where $R_{1}$ is the fraction of $\mathrm{P}_{2} \mathrm{O}_{5}$ in the $\mathrm{P}$ rock. A value of 0.3 was used, based on the work of Ward (2008). $R_{1}$ may be different in different countries; however, there is currently no information available, therefore the best option is to assume that $R_{1}$ is constant across time and different geographic regions. $R_{2}$ is the fraction of $\mathrm{P}_{2} \mathrm{O}_{5}$ in $\mathrm{P}$ fertilizer, which is determined by the type of $\mathrm{P}$ fertilizer being manufactured. This value should be the same in developed and developing countries, with a value of 0.5 according to Kabbe (2013). $F_{i}$ is the average P fertilizer demand and $W_{i}$ is P rock fertilizer fraction. By combining Equations 1 and 2, $\mathrm{P}$ demand in developing countries can be expressed as:

$D_{1}=P_{1} \times \frac{0.3 \times F_{1}}{0.5 \times W_{1}}$

P demand in developed countries can be expressed as:

$D_{2}=P_{2} \times \frac{0.3 \times F_{2}}{0.5 \times W_{2}}$

where $P_{1}, P_{2}$ are the projected populations in the developing and developed countries. The global population can be estimated from the following equation (Mohr and Evans, 2013):

$P(t)=\left[0.82+\frac{10-0.82}{\sqrt{1+1.5 \exp (-0.046 \times t-(2015.8))}}\right] \times 109$

The ' 0.82 ' in Equation (5) has been revised to 1.52 according to a recent population report (Raftery et al., 2012). The population in developed countries $\left(P_{2}\right)$ is treated as a constant value of 1.1 billion for model projections (Raftery et al., 2012). Thus, the population in developing countries will be the difference between the global population and that in the developed countries. $F_{1}$ is the average $\mathrm{P}$ demand in the developing world, which can be derived from historical $\mathrm{P}$ fertilizer supply in developing countries (Figure (4b)). $F_{2}$ is the average $P$ fertilizer demand in developed countries. It is assumed to be constant as illustrated by the trend shown in Figure 4. Based on Section 2, the average $\mathrm{P}$ fertilizer demand $\left(F_{2}\right)$ and population numbers $\left(P_{2}\right)$ from developed countries are assumed stable, and thus 
Table 4. $\mathrm{P}$ resource Estimates (Unit: in terms of $\mathrm{P}_{2} \mathrm{O}_{5}, \mathrm{Gt}$ )

\begin{tabular}{|c|c|c|c|c|c|}
\hline & Consumed & Reserve & Reserve base (raw rock) & Reserve base & URR \\
\hline Low & & & 10 & 2.0 & 9.0 \\
\hline Medium & 2.2 & 4.8 & 20 & 4.0 & 11.0 \\
\hline High & & & 40 & 8.0 & 15.0 \\
\hline
\end{tabular}

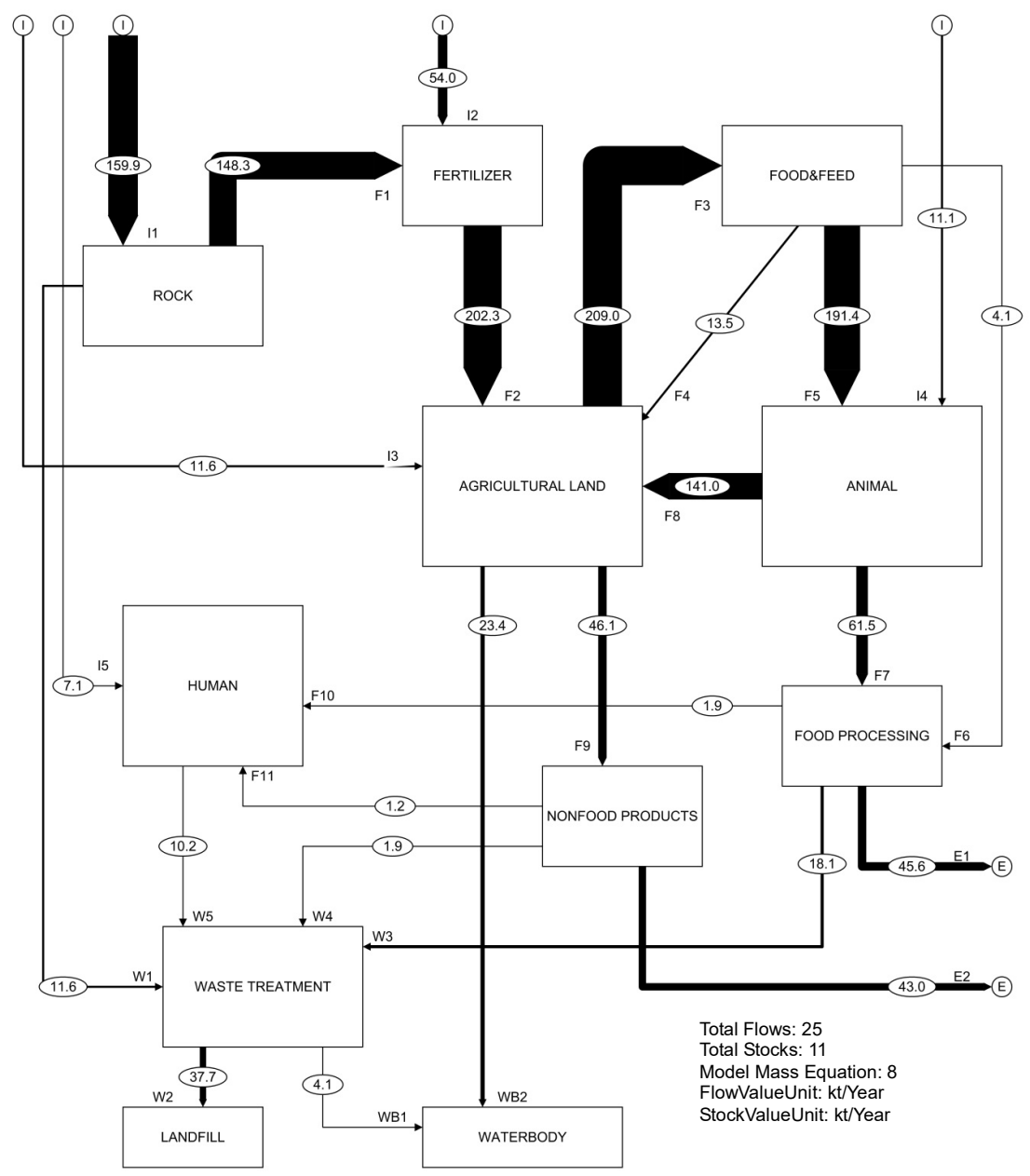

Figure 5. Substance flow analysis of the P flow system (reproduced from Li et al., 2015).

the total $\mathrm{P}$ demand of the developed world $\left(D_{2}\right)$ is assumed to be constant (at $14 \mathrm{Mt} \mathrm{P}_{2} \mathrm{O}_{5}$ for the twelve selected countries). $\mathrm{P}$ fertilizer demand in developing countries was calculated from regression analysis based on historical data with an $\mathrm{R}^{2}$ value of $0.89 . W_{1}$ and $W_{2}$ are the rock $\mathrm{P}$ fertilizer fractions, which is the ratio of $P$ rock fertilizer used to the sum of different $P$ sources for agricultural activities, discussed in Section 2.5.

\subsubsection{Supply Model}

A commonly used second order polynomial function was selected to express the relationship between $\mathrm{P}$ rock supply, $Y$, and $\mathrm{P}$ fertilizer demand:

$$
Y=\beta_{0}+\beta_{1} D_{1}+\beta_{2} D_{2}+\beta_{3} D_{1} D_{2}+\beta_{4} D_{1}^{2}+\beta_{5} D_{2}^{2}+\beta_{6} D_{1}^{2} D_{2}^{2}
$$

where $\beta_{i}$ are the model parameters, $D_{1}$ is $\mathrm{P}$ demand from developing countries and $D_{2}$ is $\mathrm{P}$ demand from developed countries. To simplify the above equation, significant terms were identified by the Orthogonal Least Squares (OLS) method developed by Chen (1989). OLS involves a Q-R decomposition of the regression matrix to calculate an error reduction ratio, which offers a simple means of ordering and can be used to select model terms according to their contribution to the performance of the model. Terms with small error reduction values were eliminated.

\subsection{P Rock Fertilizer Fraction - W}

The $\mathrm{P}$ rock fertilizer fraction, $\mathrm{W}$, is the ratio of $\mathrm{P}$ rock fertilizer applied onto agricultural land as a fraction of the total 
different $\mathrm{P}$ sources used. It is known that $\mathrm{P}$ fertilizer from mined $\mathrm{P}$ rock is one of the major sources for agricultural $\mathrm{P}$ demand. However, other P sources, such as livestock waste, plant residuals and recycled $\mathrm{P}$ from industries could also be alternative $\mathrm{P}$ sources for agricultural activities. Thus, we introduce $W$ to reflect the importance of $P$ rock fertilizer in agriculture. The relationship between different $\mathrm{P}$ sources can be shown using the substance flow analysis in Figure 5.

$W$ is the ratio of P rock fertilizer to all of the P sources being applied to agricultural land. It can be calculated using the following formula (based on information from Figure 5):

$W=\frac{F_{2}}{F_{2}+F_{4}+F_{8}+I_{3}+R}$

where $F_{2}$ is fertilizer application from $\mathrm{P}$ rock, $F_{4}$ is the plant residual that can be reused as $\mathrm{P}$ fertilizer, $F_{8}$ is $\mathrm{P}$ in livestock waste that is applied to the agricultural land, $I_{3}$ is $\mathrm{P}$ amount in atmospheric precipitation and $R$ is the amount of reused and recovered $\mathrm{P}$, mainly from waste treatment and food processing industries. Based on this method, $W$ values for countries that have previously conducted $\mathrm{P}$ flow analysis in current literature were calculated and summarized in Table 3. As shown, most developing countries do not have enough information for $W$ value quantification. Thus the known $W$ values of developing countries were averaged. The average $W$ value for developing counties was $0.65\left(W_{1}\right)$, which is larger than that in the developed counties $\left(W_{2}\right)$. This can represent the current and future $\mathrm{P}$ demand and supply system for the following reasons:

1) The applied fertilizer that is not taken up by agricultural crop and not lost to runoff may still be another agricultural $\mathrm{P}$ source. This could add to the soil phosphorus pool and contribute to future productivity. The developed countries have used $\mathrm{P}$ fertilizer for a long time, leading to higher soil $\mathrm{P}$ level than the developing countries.

2) Most developed countries have tighter P discharge limits than that in the developing counties, which would increase $P$ reuse and recycling.

3) As reported by BGS (2014), most developed countries were heavily dependent on P rock reserves. For those that do have $P$ rock resources, they are estimated to run out within the next 50 years. This would promote $P$ reuse and recycling with higher pressure from the resource demand side.

Although a dynamic $W$ value would improve the model accuracy, implementation is currently not feasible due to lacking $\mathrm{P}$ flow information. Thus two constant values were used, of 0.65 for $W_{1}$ and 0.45 for $W_{2}$ for all calculations.

\section{Results and Discussion}

\subsection{Supply Model}

$D_{1}, D_{2}, D_{2}^{2}, D_{1} D_{2}$ were found to be the significant terms in the model using the combination of the OLS and historical P rock supply from 1962 to 2007 (USGS, 2014). Thus, the model in Equation (6) is reduced to:
$Y=\beta_{0}+\beta_{1} D_{1}+\beta_{2} D_{2}+\beta_{3} D_{1} D_{2}+\beta_{5} D_{2}^{2}$

The least squares method was then used to calculate the coefficients in Equation (8), and these results are shown in Table 5.

Table 5. Result of Multiple Linear Regressions for Supply Model of Phosphorus

\begin{tabular}{lllll}
\hline & Coefficient & Standard Error & t Stat & P-Value \\
\hline$\beta_{0}$ & -77.24 & 22.4 & -3.45 & 0.0013 \\
$\beta_{1}$ & -1.03 & 0.57 & -1.79 & 0.081 \\
$\beta_{2}$ & 11.72 & 2.74 & 4.12 & 0.00017 \\
$\beta_{3}$ & 0.15 & 0.041 & 3.69 & 0.00063 \\
$\beta_{5}$ & -0.36 & 0.091 & -3.96 & 0.00028 \\
\hline
\end{tabular}

Based on the above, P demand during 1962 to 2007 was calculated and then compared with historical $\mathrm{P}$ rock supply. The results are shown in Figure 6. The model fitness was assessed using the Nash-Sutcliffe (E) model efficiency coefficient (Nash and Sutcliffe, 1970). It can be calculated using the following equation:

$E=1-\frac{\sum_{i}\left(y_{i}-f_{i}\right)^{2}}{\sum_{i}\left(y_{i}-\bar{y}\right)^{2}}$

where, $y_{i}$ is real phosphate rock production, $f_{i}$ is the predicted value and is the mean of the observed data. The $E^{2}$ value is 0.91, which means the estimates from the model in Equation (8) are in good agreement with historical demand.

\subsection{Model Validation}

Variations in the model results are due mainly to three sources: error in population estimation, error in estimated average fertilizer demand in developing countries and error from the supply demand equation - Equation (7). To validate the P supply model data on the P fertilizer demand from 1962 to 2007 (Gapminder Agriculture, 2014), population numbers (WorldBank, 2014b) and P rock supply (USGS, 2014) from 1962 to 2012 was used.

The real and predicted phosphate rock production based on real and projected numbers (Equation 8 ) are plotted in Figure 7. The difference between model projections and real data are shown in Table 6 . The difference between actual production and the projected value using the population model shows an error of -6.59 to $7.32 \%$. The modelled value does not improve in accuracy if actual population numbers, as opposed to using the modelled population, are used. Therefore the accuracy of the model appears adequate.

The reliability of the population model was examined by comparing the difference between the projected and real population numbers from 2008 to 2012 . The result indicates that the population model is quite accurate and may not influence the estimation significantly. If error from each source is assumed to follow a normal distribution with a mean of zero then the 


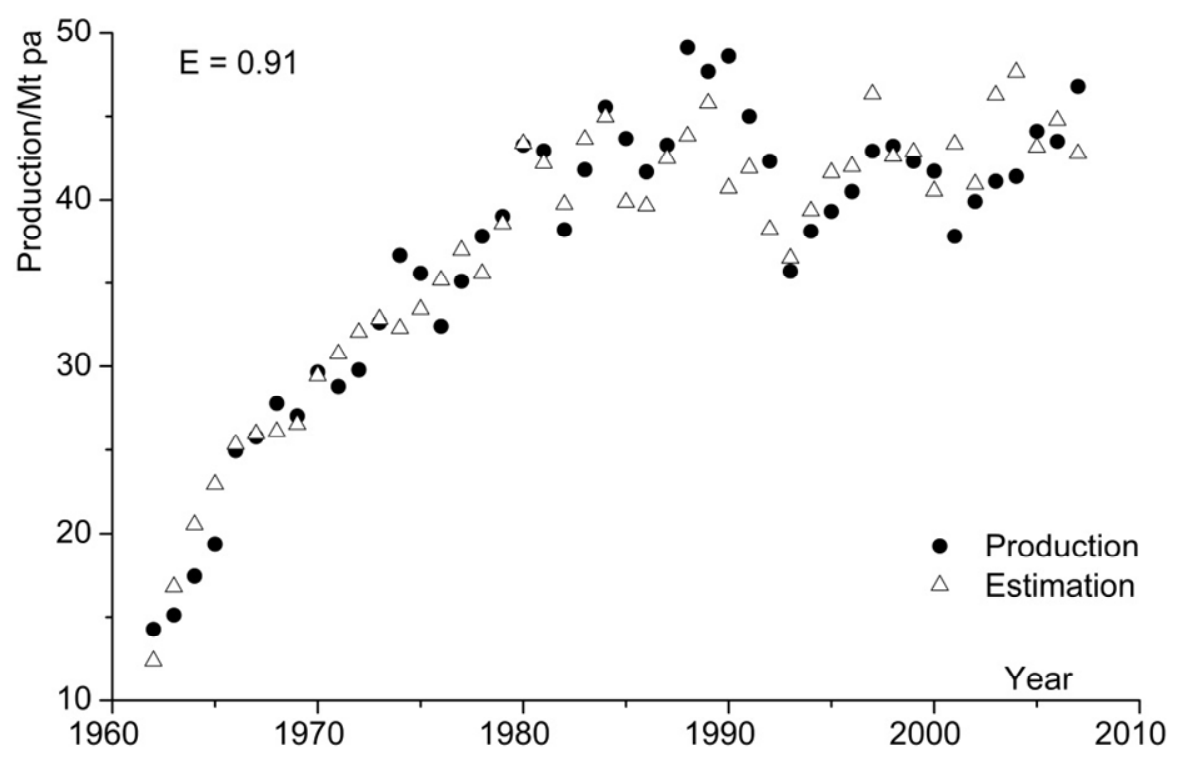

Figure 6. Comparison of historical production and calculated supply.

Table 6. Model Validation (Unit: Mt, in terms of $\mathrm{P}_{2} \mathrm{O}_{5}$ )

\begin{tabular}{llllll}
\hline Year & Model A & Model B & C & B-C error (\%) & A-C Error (\%) \\
\hline 2008 & 51.8 & 51.6 & 50.1 & 3.0 & 3.5 \\
2009 & 53.5 & 53.4 & 49.8 & 7.2 & 7.5 \\
2010 & 55.3 & 55.2 & 52.8 & 4.5 & 4.7 \\
2011 & 57.1 & 57.0 & 59.4 & -4.0 & -4.0 \\
2012 & 58.8 & 58.9 & 63.0 & -6.6 & -6.6 \\
\hline
\end{tabular}

Model A: P rock supply prediction based on projected population numbers

Model B: P rock supply prediction based on historical population

$\mathrm{C}$ : historical P rock supply

variance, $S$, can be calculated using the flowing equation:

$S=\sqrt{\sum_{1}^{n} \frac{\left(x_{i}-\hat{x}_{i}\right)^{2}}{n-1}}$

where, $x_{i}$ is the historical $\mathrm{P}$ rock supply, $\hat{x}_{i}$ is model prediction and $n$ is the years of data collected.

The $95 \%$ confidence interval can be used to indicate the reliability of the estimates, which are plotted in Figure (7b). The $95 \%$ confidence interval of the population is not included in the plot because the $S$ valued is quite small $\left(9.42 \times 10^{-6}\right)$, making the confidence interval nearly the same as the predicted value. To estimate the prediction error from Equation (7), the Monte Carlo simulation method was used.

This is a broad class of computational algorithms that rely on repeated random sampling (population and fertilizer demand), running simulations many times $(10,000)$ to obtain the distribution of an unknown probabilistic entity ( $\mathrm{P}$ supply in this study). This process was used to estimate the variance $\left(S^{2}\right)$. It was then used to generate the $95 \%$ confidence interval of $\mathrm{P}$ rock supply and is plotted in Figure $7(\mathrm{c})$. As can be seen, the confidence interval should be wider when the prediction hori- zon becomes larger. The same method was used to derive the estimates of the error from 2008 to 2012, which is plotted in Figure 8. As shown, the estimate lies within the $95 \%$ confidence interval, so the model results are acceptable.

\subsection{Depletion Time}

Based on the P rock supply and URR, the P rock depletion time can be determined by the equation below:

$$
R=\sum_{i=2013}^{n} P_{i}
$$

where, $R$ is an accumulation of $\mathrm{P}$ rock supple, $P_{i}$ is annual $\mathrm{P}$ rock supply and $n$ is the depletion time. By integrating the annual $P$ rock supply, the effect of different reserve quantities on the estimated depletion year is shown in Table 7.

By plotting the $R$ to URR ratio, a trend analysis between the depletion year and URR is described in Figure 9. The depletion is estimated to occur within $70 \sim 140$ years based on different URR. Comparison between the model developed in this work and past research is shown in Table 7. The main difference comes from the estimated amount of reserve base, 


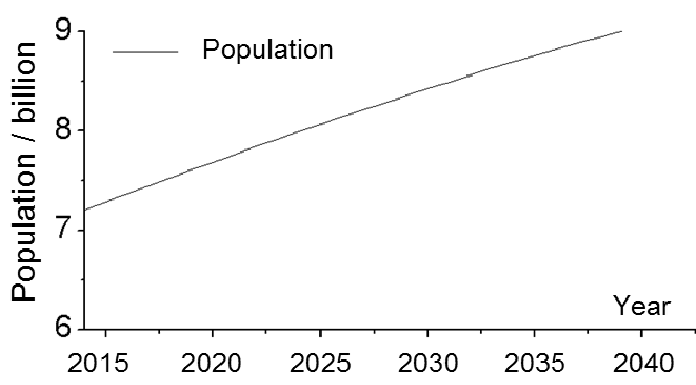

a. Future population in developing countries

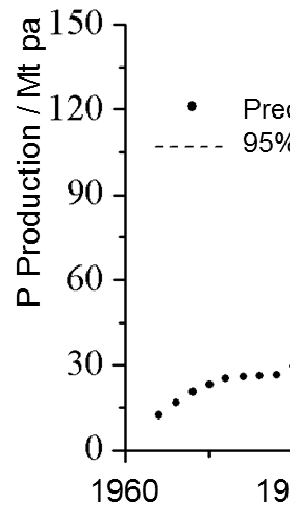

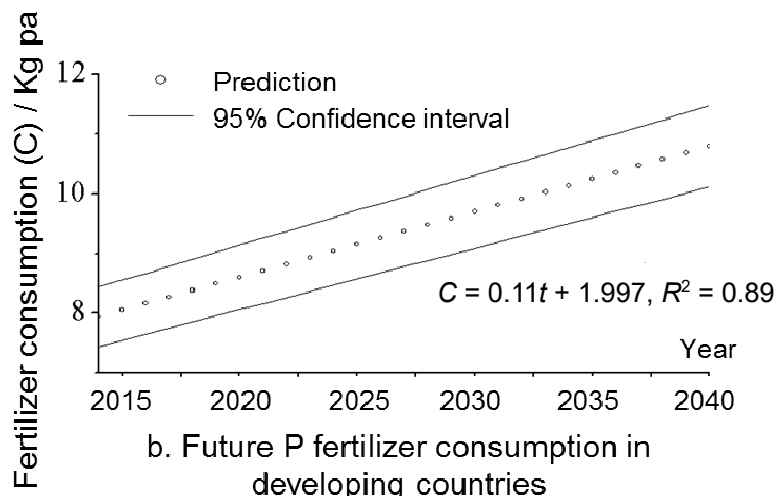
developing countries 


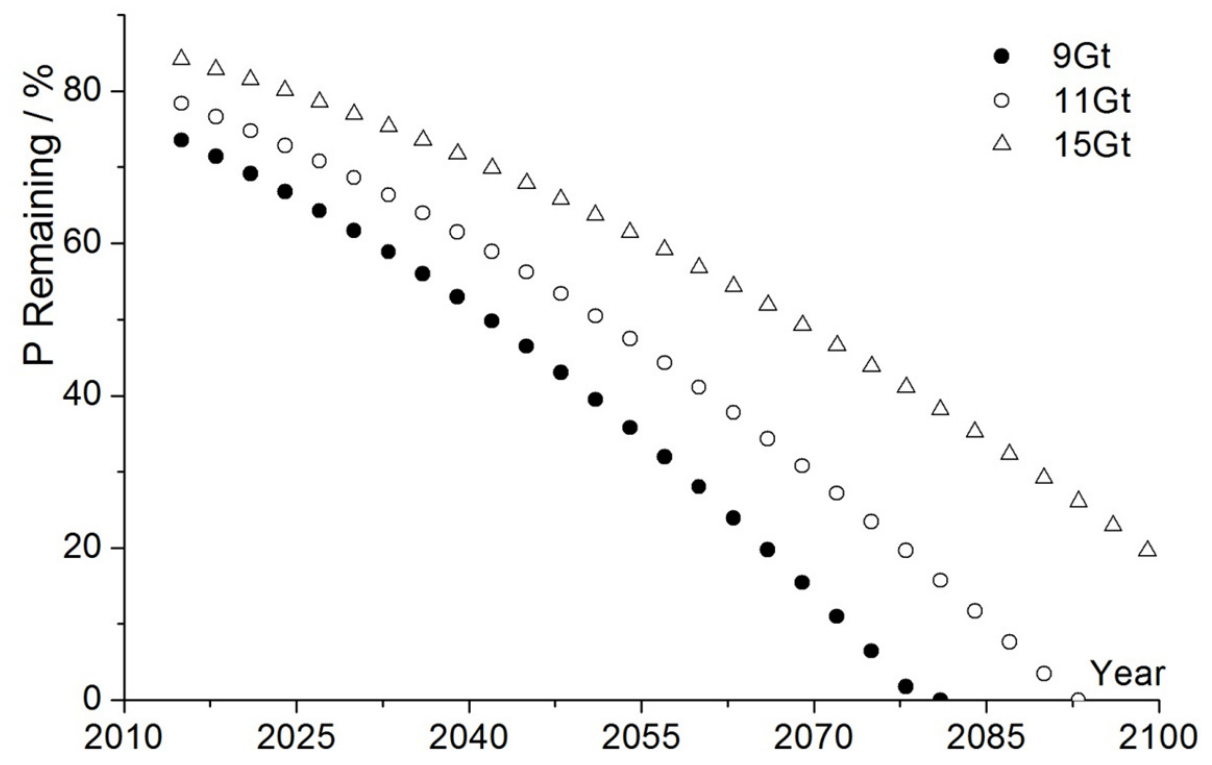

Figure 9. Trend analyses between depletion time and reserves.

the population is projected to grow linearly in the near future. Furthermore, most developing countries still require large amounts of $\mathrm{P}$ rock due to the changing soil phosphorus level and diet structure. Because both the economic situation and politics may significantly influence production, this model could only be used for gross trend prediction. It appears that phosphorus demand behaviour may follow five stages:

1) Unrestricted growth when supply follows the requirements of demand;

2) Restricted growth when supply is constrained by demand and environment limitations;

3) Balanced stage when supply and demand are stable;

4) Shortage stage when demand is decided by production;

5) A new stage when demand is mainly supplied from recovered resources or replaced.

The $W$ value is expected to decrease with the depletion of $P$ rock reserves and the emergence of other P sources. Historical P rock supply from USGS (2014) and BGS (2014) indicates that most developed countries are now undergoing transformation from stage 2 to stage 3. Most developing countries, however, are still in stage 1, although a few are experiencing the transformation from stage 1 to stage 2. It is under this assumption that the presented model is composed of developed and developing countries. $\mathrm{P}$ demand in developing countries may move into stages 2 or 3 in the future, and the demand behaviour worldwide may also change when phosphorus becomes a scarce resource. However, due to a lack of historical data (only 45 years) and lack of other supporting information (soil phosphorus level and diet structure, etc.) it is difficult to predict the robustness of the model in the long term. This model has the advantage that the parameters of population and the P rock fertilizer to all $\mathrm{P}$ sources ratio can be revised with time, thus making the model flexible. An accurate prediction, that can be revised if the situation changes, can help decision makers plan appropriately and design a $\mathrm{P}$ management system that is suita- ble in terms of long term phosphorous goals. Thus it can be used to set specific phosphate rock supply and recovery rates to sustain the utilization of this resource.

Table 7. Proposed Peaks Time and Depletion Year

\begin{tabular}{lll}
\hline URR (Gt) & Depletion time & Reference \\
\hline 13.3 & $\sim 150$ & Herring and Fantel, 1993 \\
9.7 & $\sim 130$ & Cordell et al., 2010 \\
111.5 & $>200$ & Van Vuuren et al., 2010 \\
27.0 & $\sim 130$ & Van Vuuren et al., 2010 \\
9.0 & $\sim 70$ & proposed model \\
11.0 & $\sim 80$ & proposed model \\
15.0 & $\sim 110$ & proposed model \\
\hline
\end{tabular}

URR: Ultimately recoverable resources, in terms of $\mathrm{P}_{2} \mathrm{O}_{5}$.

\section{Phosphorus Management}

From the above discussion, $\mathrm{P}$ is an essential element for life, and $\mathrm{P}$ rock a non-renewable resource and is expected to deplete within 140 years (Figure 9). Unlike the peak oil theory, there is no substitute for P rock (Scholz and Wellmer, 2013). At the same time, nearly $95 \%$ of mined $\mathrm{P}$ is lost to the environment, mostly due to agriculture and animal farming. Thus, $\mathrm{P}$ recovery is concluded to be one of the most important routes to prevent phosphorus rock shortages. A conceptual $\mathrm{P}$ management system is proposed based on this. The system is composed of three participants (organizations, companies and industry, and governments), any two of these components are bidirectionally affected by each other from three aspects: technology, policy and culture. Within this system, universities and research organizations are education and research providers developing technologies to improve utilization efficiency. Companies and industry are promoters and verify engineering methods for technologies and policies in the market. Governments make policies that both focus on planning strategies for current resource 


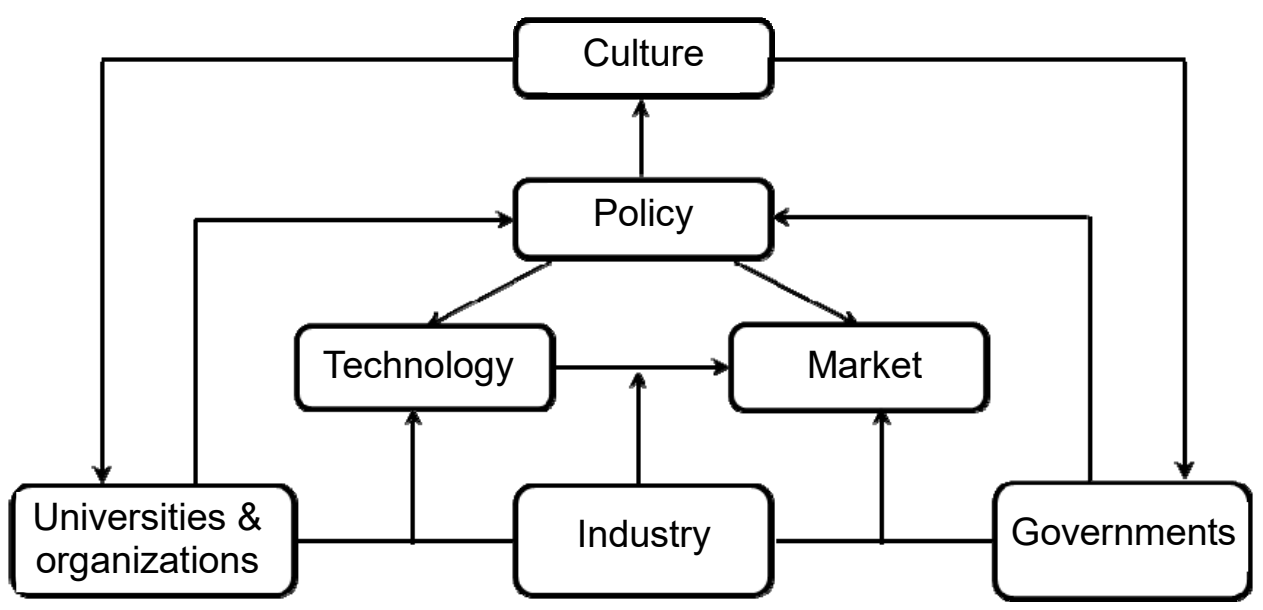

Figure 10. Proposed phosphorus management systems.

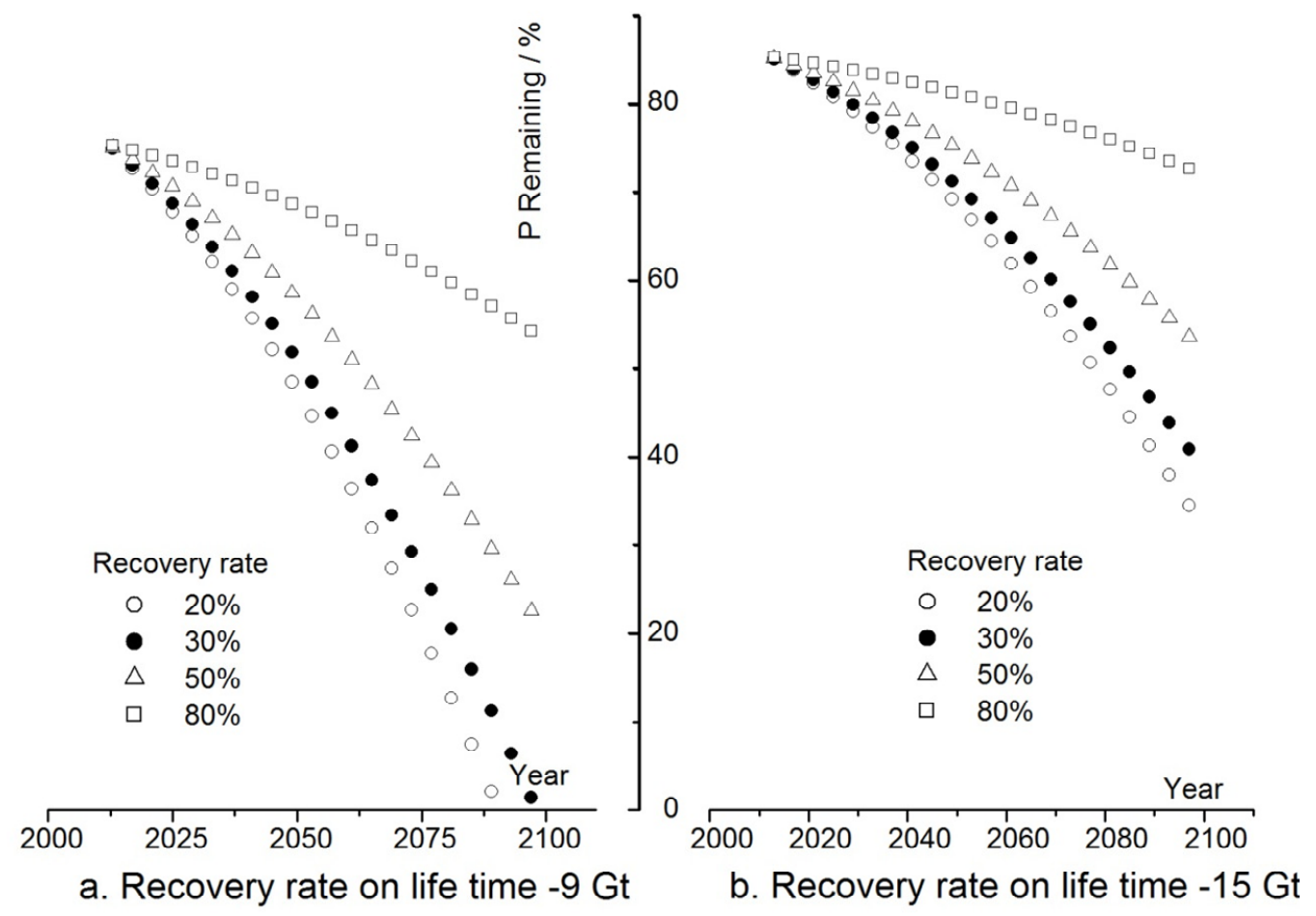

Figure 11. Trend analyses between recovery rate and life time.

management and encourage actions that reuse or recycle diffused P. With the common effort of the market, the educational and research institutes, and governments, a new $\mathrm{P}$ utilization culture could be formed to shape the behaviour of individuals in society. This might correct current public misunderstandings (e.g., current $\mathrm{P}$ treatment is targeting $\mathrm{P}$ removal for environment regulations, but not $\mathrm{P}$ recovery for resource management) of waste recycling.

Organizations supporting such a system are emerging: the Sustainable P Initiative (USA), the Sustainable Phosphorus Research Coordination Network (USA), Sustainable Phosphorus Future (Australia) and the Phosphorus Recycling Pro- motion Council (Japan). Furthermore, international scale organizations have also been established: Southern ExtensionResearch Activity 17, the European Sustainable Phosphorus Platform, the Global Traps and Global phosphate forum. These organizations are either universities or government components, as shown in Figure 10. At the same time, emerging policies from Sweden and Germany have proposed a minimum $P$ recovery rate from wastewater in the near future, and companies in the Netherlands have also made an agreement on the $\mathrm{P}$ value chain with the aim of recycling as much $\mathrm{P}$ as possible. However, these actions are insufficient. Slow release fertilizer should be developed to avoid direct loss during application, as 
well as new cultivation methods (Scholz et al., 2013). Plant P up taking process should be studied to improve phosphorus utilization efficiency. Most importantly, recovery rather than removal techniques should be developed during animal waste and water sludge treatment processes (Kabbe, 2013, Sample et al., 2012). The purpose of such a system is to extend the depletion time of phosphorus rock as long as possible. Such an effect can be evaluated by the combination of P rock supply and designed recovery rate. The equation can be derived as:

$R=\sum_{i=2013}^{n}(1-X) P_{i}$

where, $X$ is the recovery rate, which is consists of $\mathrm{P}$ reuse (animal manure application) and recovery (e.g. struvite precipitation) activities. The depletion rate is shown in Figure 11, by integrating the annual P rock supply.

Recovery rates of $0.2,0.3,0.5$ and 0.8 were chosen to explore their effect on depletion time. An extension of 50 years can be achieved if $50 \%$ of the current wasted phosphorus is recovered under the lowest URR level (Figure (11a)). This number will be much larger when URR is changed to a mid or high level (Figure (11b)). However, a higher recovery rate might increase process cost and make the whole management system economically unfeasible. Thus, future work on policy design to achieve a reasonable recovery rate based on the prediction result is recommended.

\section{Conclusions}

This paper develops a method for projecting the future phosphorus rock consumption based on the phosphorus demand and supply in developed and developing countries due to population growth. The proposed model was validated using real phosphate rock production data between 2008 and 2012 and the results indicate that the current phosphate rock reserves will be depleted in approximately $70 \sim 140$ years.

Future phosphorus supply is expected to increase in the next 20 years, due to the increasing demand from population growth and soil phosphorous required in developing counties. A conceptual phosphorus management system is proposed and the effect of phosphorus recovery was thus evaluated. It indicated that the required waste recovery to defer the phosphorus rock depletion time by 50 years is approximately $50 \%$, which is significant. Therefore, the current phosphorus research should focus on recovery, as opposed to removal.

Acknowledgements. We would like to thank Professor Yue Fei Huang from Tsinghua University, P.R China for the suggestions on model development.

\section{References}

Bennett, E., and Elser, J. (2011). Phosphorus cycle: A broken biogeochemical. Nature, 478, 29-31. http://dx.doi.org/10.1038/478029a

BGS (2014). Phosphate Rock Production by Country. https://www. bgs.ac.uk.
Burt, D., Dumas, M., Springer, N., and Vaccari, D.A. (2013). Global phosphorus: Geological sources and demand-driven production, Phosphorus, Food, and Our Future, Oxford University Press, Oxford, pp. 40-63, 2013. http://dx.doi.org/10.1093/acprof:osobl/9780 199916832.003.0003

Chen, S., Billings, S.A., and Luo, W. (1989). Orthogonal least squares methods and their application to non-linear system identification. Int. J. Control, 50(5), 1873-1896. http://dx.doi.org/10.1080/002071 78908953472

Cooper, J., and Carliell-Marquet, C. (2013). A substance flow analysis of phosphorus in the UK food production and consumption system. Resour. Conserv. Recycl., 74, 82-100. http://dx.doi.org/10.1016/j.re sconrec.2013.03.001

Cooper, J., Lombardi, R., Boardman, D., and Carliell-Marquet, C. (2011). The future distribution and production of global phosphate rock reserves. Resour. Conserv. Recycl., 57, 78-86. http://dx.doi. org/10.1016/j.resconrec.2011.09.009

Cordell, D., Drangert, J.O., and White, S. (2009). The story of phosphorus: Global food security and food for thought. Global Environ. Change, 19(2), 292-305.http://dx.doi.org/10.1016/j.gloenvcha.2008. 10.009

Déry, P., and Anderson, B. (2007). Peak phosphorous. Energy Bulltin, $1-5$.

May, D., Prior, T., Cordell, D., Giurco, D. (2012). Peak minerals: Theoretical foundations and practical application. Nat. Resour. Res., 21(1), 43-60. http://dx.doi.org/10.1007/s11053-011-91 63- z

Gapminder Agriculture (2014). List of indicators in Gapminder World 2014. http://www.gapminder.org/data/

Galvez-Sola, L., Morales, J., Mayoral, A.M., Marhuenda-Egea, F.C., Martinez-Sabater, E., Perez-Murcia, M.D., Bustanante, M.A., Paredes, C., and Moral, R. (2010). Estimation of phosphorus content and dynamics during composting: Use of near infrared spectroscopy. Chemosphere, 78(1), 13-21. http://dx.doi.org/10.1016/j.chemospher e.2009.09.059

Herring, J.R., and Fantel, R.J. (1993). Phosphate rock demand into the next century: Impact on world food supply. Nonrenewable Resour., 2(3), 226-246. http://dx.doi.org/10.1007/BF02257917

Kabbe, C. (2013). The Limited Resources of Phosphorus and How to Close the Phosphorus Cycle, Factor X, Springer, 261-270. http://dx. doi.org/10.1007/978-94-007-5712-7_17

Koppelaar, R.H.E.M., and Weikard, H.P. (2013). Assessing phosphate rock depletion and phosphorus recycling options. Global Environ. Change, 23(6), 1454-1466. http://dx.doi.org/10.1016/j.gloenvcha. 2013.09.002

Li, B., Boiarkina, I., Young, B., and Yu, W. (2015). Substance flow analysis of phosphorus within New Zealand and comparison with other countries. Sci. Total Environ., 527-528, 483-492. http://dx. doi.org/10.1016/j.scitotenv.2015.04.060

Lutz, W., Sanderson, W., and Scherbov, S. (2001). The end of world population growth. Nature, 412, 543-545. http://dx.doi.org/10.103 $8 / 35087589$

Mohr, S., and Evans, G. (2013). Projections of future phosphorus production, Philica.com, article number 380, 2013.

Nash, J.E., and Sutcliffe, J.V. (1970). River flow forecasting through conceptual models, Part I-A discussion of principles, J. Hydrol., 10(3), 282-290. http://dx.doi.org/10.1016/0022-1694(70)90255-6

Raftery, A.E., Li, N., Gerland, P., and Heilig, G.H. (2012). Bayesian probabilistic population projections for all countries, Proc. of the National Academy of Sciences, 109, 13915-13921. http://dx.doi. org/10.1073/pnas.1211452109

Rawashdeh, R., and Maxwell, P. (2011). The evolution and prospects of the phosphate industry. Miner. Econ., 24(1), 15-27. http://dx.doi. org/10.1007/s13563-011-0003-8

Sample, D.J., Grizzard, T.J., Sansalone, J., Davis, A.P., Roseen, R.M., 
and Walker, J. (2012). Assessing performance of manufactured treatment devices for the removal of phosphorus from urban stormwater. J. Environ. Manage., 113, 279-291. http://dx.doi.org/10.101 6/j.jenvman.2012.08.039

Scholz, R.W., Ulrich, A.E., Eilitta, M., and Roy, A. (2013). Sustainable use of phosphorus: A finite resource. Sci. Total Environ., 461-462, 799-803. http://dx.doi.org/10.1016/j.scitotenv.2013.05.043

Scholz, R.W., and Wellmer, F.W. (2013). Approaching a dynamic view on the availability of mineral resources: What we may learn from the case of phosphorus? Global Environ. Change, 23(1), 11-27. http://dx.doi.org/10.1016/j.gloenvcha.2012.10.013

Sinding-Larsen, R., and Wellmer, F.W. (2012). Non-renewable resource issues: Geoscientific and societal challenges: An introduction, Non-Renewable Resource Issues, pp 1-19, 2012. http://dx.doi.org/ 10.1007/978-90-481-8679-2_1

Sverdrup, H.U., and Ragnarsdottir, K.V. (2011). Challenging the planetary boundaries II: Assessing the sustainable global population and phosphate supply, using a systems dynamics assessment model. Appl. Geochem., 26, S307-S310. http://dx.doi.org/10.1016/ j.apgeochem.2011.03.089

USGS (2014). Phosphate Rock Production by Country. http://mine rals.usgs.gov/minerals/pubs/commodity/phosphate_rock/.

Vaccari, D.A. (2011). Sustainability and the phosphorus cycle: Inputs, outputs, material flow, and engineering. Environ. Eng., 12, 29-38.

Van Kauwenbergh, S.J., Stewart, M., and Mikkelesen, R. (2013). World reserves of phosphate rock: A dynamic and unfolding story. Better Crop. Plant Food, 97, 18-20.

Van Vuuren, D.P., Bouwman, A.F., and Beusen, A.H.W. (2010). Phosphorus demand for the 1970-2100 period: A scenario analysis of resource depletion. Global Environ. Change, 20(3), 428-439. http: //dx.doi.org/10.1016/j.gloenvcha.2010.04.004

Wang, E., Ridoutt, B.G., Luo, Z.K., and Probert, M.E. (2013). Using systems modelling to explore the potential for root exudates to increase phosphorus use efficiency in cereal crops. Environ. Model. Software, 46, 50-60. http://dx.doi.org/10.1016/j.envsoft.2013.02. 009

Walan, P., Davidsson, S., Johansson, S., Hook, M. (2014). Phosphate rock production and depletion: regional disaggregated modeling and global implications, Resour. Conserv. Recycl., 93, 178-187

Ward, J. (2008). Peak phosphorus: Quoted reserves vs. production history. Energy Bulletin.

WorldBank (2014a). How we Classify Countries. http://data.world bank.org/about/country-classifications.

WorldBank (2014b). Coutry indicator. http://data.worldbank.org/indi cator. 